\title{
Synergistic inhibitory effects of cetuximab and curcumin on human cisplatin-resistant oral cancer CAR cells through intrinsic apoptotic process
}

\author{
CHIN-FU CHEN ${ }^{1}$, CHI-CHENG LU ${ }^{2}$, JO-HUA CHIANG ${ }^{3}$, HONG-YI CHIU $^{2}$, JAI-SING YANG ${ }^{4}$, \\ CHAO-YING LEE ${ }^{5}$, TZONG-DER WAY ${ }^{6}$ and HAO-JEN HUANG ${ }^{1,7}$
}

\begin{abstract}
${ }^{1}$ Department of Life Sciences, National Cheng Kung University, Tainan $701 ;{ }^{2}$ Department of Pharmacy, Buddhist Tzu Chi General Hospital, Hualien 970; ${ }^{3}$ Department of Nursing, Chung Jen Catholic Junior College, Chiayi County 622; ${ }^{4}$ Department of Medical Research, China Medical University Hospital, China Medical University; Departments of ${ }^{5}$ Pharmacy and ${ }^{6}$ Biological Science and Technology, China Medical University, Taichung 404;

${ }^{7}$ Institute of Tropical Plant Sciences, National Cheng Kung University, Tainan 701, Taiwan, R.O.C.
\end{abstract}

Received November 15, 2017; Accepted August 1, 2018

DOI: $10.3892 / 01.2018 .9418$

\begin{abstract}
Cetuximab, an epidermal growth factor receptor (EGFR)-targeting monoclonal antibody (mAb), is a novel targeted therapy for the treatment of patients with oral cancer. Cetuximab can be used in combination with chemotherapeutic agents to prolong the overall survival rates of patients with oral cancer. Curcumin is a traditional Chinese medicine, and it has been demonstrated to have growth-inhibiting effects on oral cancer cells. However, information regarding the combination of cetuximab and curcumin in drug-resistant oral cancer cells is lacking, and its underlying mechanism remains unclear. The purpose of the present study was to explore the oral anticancer effects of cetuximab combined with curcumin on cisplatin-resistant oral cancer CAR cell apoptosis in vitro. The results demonstrated that combination treatment synergistically potentiated the effect of cetuximab and curcumin on the suppression of cell viability and induction of apoptosis in CAR cells. Cetuximab and curcumin combination induced apoptosis and dramatically increased caspase- 3 and caspase- 9 activities compared with singular treatment. Combination treatment also markedly suppressed the protein expression levels of EGFR and mitogen-activated protein kinases (MAPKs) signaling (phosphorylation of ERK, JNK and p38).
\end{abstract}

Correspondence to: Dr Hao-Jen Huang, Department of Life Sciences, National Cheng Kung University, 1 University Road, Tainan 701, Taiwan, R.O.C.

E-mail: haojen@mail.ncku.edu.tw

Dr Tzong-Der Way, Department of Biological Science and Technology, China Medical University, 91 Hsueh-Shih Road, Taichung 404, Taiwan, R.O.C.

E-mail: tdway@mail.cmu.edu.tw

Key words: cetuximab, curcumin, epidermal growth factor receptor, MAPK signaling, cisplatin-resistant oral cancer CAR cells
The results demonstrated that co-treatment with cetuximab and curcumin exerts synergistic oral anticancer effects on CAR cells through the suppression of the EGFR signaling by regulation of the MAPK pathway.

\section{Introduction}

Epidermal growth factor receptor (EGFR) is a receptor tyrosine kinase in the cell transmembrane that serves an essential role in proliferation, metastasis, angiogenesis and chemo-resistance of oral cancer cells $(1,2)$. More than $80 \%$ patients with oral cancer and oral cancer cell lines exhibit overexpression of EGFR (3-6). High expression of EGFR protein in oral cancer is associated with poor prognosis, decreased survival time and increased metastatic potential $(7,8)$. Inhibition of EGFR and regulation of downstream signaling represents a novel approach for oral cancer therapy $(9,10)$. Various strategies have been developed to disrupt EGFR function and to interfere with downstream signaling $(11,12)$. Anti-EGFR mAbs and EGFR inhibitors have been investigated the most extensively $(3,5,13)$.

Cetuximab is an EGFR-targeting mAb and the first novel targeted agent for oral cancer treatment to obtain Food and Drug Administration approval in the United States $(11,13)$. In combination with chemotherapeutic agents, cetuximab has been demonstrated to increase the overall survival rate of patients with oral cancer, and to have less toxicity $(7,10,14)$. In oral cancer therapy, combination of cetuximab with cisplatin, 5-fluorouracil (5-FU), docetaxel (Taxotere) or paclitaxel (Taxol) has become the new standard advanced treatment $(8,9,15,16)$.

Curcumin is a traditional Chinese medicine isolated from the rhizome of Curcuma longa (17-20). Curcumin has been shown to exert anti-inflammatory, anti-oxidant, and anticancer effects, it is pharmacologically safe and has minimal toxicity $(17,19,20)$. The anticancer activities of curcumin are attributable to its anti-proliferative, anti-angiogenic, anti-metastatic, pro-apoptotic and autophagic characteristics (21-25). In vitro studies reported that curcumin inhibited cell proliferation in various oral cancer 
cell lines, including CAL 27, 1483, SCC-1, SCC-9, KB, SAS and SCC15 (26). Curcumin also suppressed EGFR expression and its downstream signaling molecules (NF-kB, JNK, p38 and ERK) which are vital for oral cancer pathogenesis (27-29). Furthermore, curcumin enhanced cisplatin cytotoxicity in $\mathrm{PE} / \mathrm{CA}-\mathrm{PJ} 15$ cells in vitro (30). The combination of 5-FU, doxorubicin or cisplatin with curcumin exhibited inhibited proliferation and induced apoptotic cell death of NT8e oral squamous cell carcinoma cells (31). However, the molecular mechanism of the suppression of cell proliferation and apoptotic induction of drug-resistant oral cancer cells following co-incubation with cetuximab and curcumin remains poorly understood. Herein, the synergistic effects and underlying molecular mechanism of the effect of combined treatment of cetuximab and curcumin in cisplatin-resistant oral cancer CAR cells was explored.

\section{Materials and methods}

Chemicals and reagents. Erbitux (the active ingredient of cetuximab) was provided by Hualien Tzu Chi Hospital (Taiwan) and originally purchased from Merck KGaA (Darmstadt, Germany). Dulbecco's modified Eagle's medium (DMEM), fetal bovine serum (FBS), L-glutamine and penicillin-streptomycin solution were purchased from HyClone (GE Healthcare, Logan, UT, USA). Caspase-3 and Caspase-9 colorimetric assay kits were sourced from R\&D Systems (Minneapolis, MN, USA). All primary antibodies and anti-mouse/-rabbit immunoglobulin G (IgG) horseradish peroxidase (HRP)-conjugated antibodies were purchased from GeneTex (Hsinchu, Taiwan). Curcumin, Thiazolyl Blue Tetrazolium Bromide (MTT) and other reagents were of analytical grade from Sigma-Aldrich (Merck KGaA, Darmstadt Germany), unless otherwise stated.

Cell culture. The human oral cancer cell line, CAL 27, was obtained from American Type Culture Collection (ATCC; Manassas, VA, USA). The cisplatin-resistant subline of CAL 27, CAR, was generated in our laboratory, as previously described (32-34) and exposed to increasing concentrations of cisplatin to generate a stable subline with resistance to $\geq 80 \mu \mathrm{M}$ cisplatin. CAR cells were maintained in an environment of 5\% $\mathrm{CO}_{2}$ at $37^{\circ} \mathrm{C}$ in DMEM supplemented with $10 \% \mathrm{FBS}, 2 \mathrm{mM}$ L-glutamine, $100 \mu \mathrm{g} / \mathrm{ml}$ streptomycin, $100 \mathrm{Units} / \mathrm{ml}$ penicillin and $80 \mu \mathrm{M}$ cisplatin. Cetuximab was diluted with cultured medium (DMEM with supplementation as described above), and curcumin was dissolved in dimethyl sulfoxide (DMSO).

Cytotoxicity assay. Cell viability was estimated by MTT assay. In brief, CAR cells $\left(1 \times 10^{4}\right.$ cells/well $)$ were plated in 96-well tissue culture plates and treated with curcumin $(10,20$, 40 or $50 \mu \mathrm{M})$, cetuximab $(10,20,40$ or $50 \mu \mathrm{g} / \mathrm{ml})$ or $20 \mu \mathrm{g} / \mathrm{ml}$ cetuximab and 10,20 or $40 \mu \mathrm{M}$ curcumin for $24 \mathrm{~h}$. Following exposure and removal of the medium, the cells were cultured with $0.5 \mathrm{mg} / \mathrm{ml}$ MTT for an additional $2 \mathrm{~h}$. The blue formazan product was dissolved in $100 \mu \mathrm{l}$ DMSO and spectrophotometrically measured at a wavelength of $570 \mathrm{~nm}$ using an ELISA plate reader (Anthos Labtec Instruments $\mathrm{GmbH}$, Salzburg, Austria), as previously described (35). The percentage of living cells was calculated, and the ratio of optical density of the experimental wells and control wells was calculated as \% of control. Combination index (CI) was determined using the Chou-Talalay method, as previously described (36). A value $<1.0$ indicated a synergistic effect.

Morphological determination. CAR cells ( $1 \times 10^{5}$ cells per well) were seeded into a 24 -well plate and treated with $20 \mu \mathrm{g} / \mathrm{ml}$ cetuximab and 10,20 or $40 \mu \mathrm{M}$ curcumin for $24 \mathrm{~h}$. The cells were visualized using a phase-contrast microscope to check for apoptotic characteristics and photographed, as previously described (37).

Caspase-3 and -9 activity measurement. CAR cells were seeded at a density of $5 \times 10^{6}$ cells per $75 \mathrm{~T}$ flask and incubated with $20 \mu \mathrm{g} / \mathrm{ml}$ cetuximab, $40 \mu \mathrm{M}$ curcumin, or $20 \mu \mathrm{g} / \mathrm{ml}$ cetuximab and $40 \mu \mathrm{M}$ curcumin for $24 \mathrm{~h}$. The cell lysate was collected, and the cell fraction was analyzed for caspase-3/-9 activity using Caspase-3 and Caspase-9 Colorimetric Assay kits (R\&D Systems, Inc., Minneapolis, MN, USA), according to the manufacturer's protocol.

Western blot analysis. CAR cells $\left(5 \times 10^{6}\right.$ cells per $75 \mathrm{~T}$ flask) were treated with either $20 \mu \mathrm{g} / \mathrm{ml}$ cetuximab, $40 \mu \mathrm{M}$ curcumin or both for $24 \mathrm{~h}$. Then, the cells were harvested and lysed with PRO-PREP Protein Extraction Solution (iNtRON Biotechnology, Seongnam-si, Gyeonggi-do, Korea). The protein concentration was determined using the Pierce BCA protein assay kit (Thermo Fisher Scientific, Inc., Waltham, MA, USA), and $40 \mu \mathrm{g}$ protein was loaded per lane of $8-10 \%$ SDS-PAGE gels. The protein was thereafter transferred into Immobilon-P Transfer Membranes (Merck Millipore, Billerica, MA, USA). Each membrane was blocked in 5\% non-fat dry milk in phosphate-buffered saline with Tween-20 (PBST; $8 \mathrm{mM} \mathrm{Na}_{2} \mathrm{HPO}_{4}, 0.15 \mathrm{M} \mathrm{NaCl}, 2 \mathrm{mM} \mathrm{KH}_{2} \mathrm{PO}_{4}, 3 \mathrm{mM}$ $\mathrm{KCl}, 0.05 \%$ Tween-20, $\mathrm{pH}$ 7.4) for $1 \mathrm{~h}$. The membraned were then incubated at $4^{\circ} \mathrm{C}$ overnight with primary antibodies against p-EGFR (cat. no. GTX61353), EGFR (cat. no. GTX100448), p-ERK (cat. no. GTX59568), ERK (cat. no. GTX59618), p-JNK (cat. no. GTX52326), JNK (cat. no. GTX52360), p-p38 (cat. no. GTX48614), p38 (cat. no. GTX110720) (all 1:1,000 dilution), and $\beta$-actin (cat. no. GTX109639) (1:5,000 dilution) (GeneTex). Following washing with PBST, the membrane was incubated with appropriate anti-mouse (cat. No GTX213111-01)/-rabbit (cat. no. GTX213110-01) HRP-conjugated secondary antibodies (1:10,000 dilution) for $1 \mathrm{~h}$ at room temperature. Proteins were visualized by enhanced chemiluminescence (Immobilon Western Chemiluminescent HRP Substrate; Merck Millipore) and using the LAS-4000 imaging system (Fuji, Tokyo, Japan), as previously described (38-40). The density of the immunoblots was analyzed using Image J (version 1.47; National Institutes of Health, Bethesda, MA, USA).

Statistical analysis. The values are presented as the mean \pm standard deviation of 3 independent experiments. Comparisons between the drug-treated and -untreated groups were made using one-way analysis of variance followed by Dunnett's test using SPSS software (version 16.0; SPSS, Inc., Chicago, IL, USA). $\mathrm{P}<0.001$ was considered to indicate a statistically significant difference. 


\section{Results}

Effects of curcumin, cetuximab and combination treatment on the viability of cisplatin-resistant oral cancer $C A R$ cells. The cytotoxicity of curcumin and cetuximab on CAR cells. The cells were cultured with various concentrations of curcumin $(10,20,40$ or $50 \mu \mathrm{M})$, or cetuximab $(10,20$, 40 or $50 \mu \mathrm{g} / \mathrm{ml}$ ), or $20 \mu \mathrm{g} / \mathrm{ml}$ cetuximab combined with 10 , 20 or $40 \mu \mathrm{M}$ curcumin, for $24 \mathrm{~h}$. Cell viability was evaluated by MTT assay. The results demonstrated that curcumin markedly decreased the viability of CAR cells in a concentration-dependent manner, and the viability at 20,40 and $50 \mu \mathrm{M}$ was $87.1,48.5$ and $12.3 \%$, respectively (Fig. 1A). It was also revealed that 20,40 and $50 \mu \mathrm{g} / \mathrm{ml}$ cetuximab reduced CAR-cell viability to $85.8,72.8$ and $67.4 \%$, respectively, another concentration-dependent effect (Fig. 1B). However, $10 \mu \mathrm{g} / \mathrm{ml}$ cetuximab demonstrated no significant inhibition. Thus, CAR cells were more sensitive to curcumin than that to cetuximab. The cells were treated with a combination of $20 \mu \mathrm{g} / \mathrm{ml}$ cetuximab and $0,10,20$ and $40 \mu \mathrm{M}$ curcumin for $24 \mathrm{~h}$, and significant potentiation of cytotoxicity and synergy of CAR cells was demonstrated by viabilities of 83.7, 75.7, 70.3 and $38.6 \%$, respectively (Fig. 1C). The combination index (CI) was $0.9,0.8$ and 0.6 at treatments of $20 \mu \mathrm{g} / \mathrm{ml}$ cetuximab and 10,20 and $40 \mu \mathrm{M}$ of curcumin, respectively, indicating the synergistic effects of cetuximab and curcumin. The results imply that a significant increase in cytotoxic effects was achieved with simultaneous administration of cetuximab and curcumin to CAR cells.

Effects of curcumin and cetuximab, alone or combined, on the morphology of CAR cells. Photomicrographs demonstrated that combined treatment resulted in cell shrinkage, cytoplasmic membrane blebbing and cell death, compared with exposure to $20 \mu \mathrm{g} / \mathrm{ml}$ cetuximab alone and untreated control (Fig. 2). Furthermore, combined treatment resulted in increased inhibition in viability of CAR cells compared with single-drug (cetuximab) treatment and untreated control (Fig. 2). These data indicated that concurrent exposure to cetuximab and curcumin synergistically induced apoptosis and reduced proliferation of CAR cells.

Effects of curcumin and cetuximab, alone or in combination, on caspase-3/-9-dependent apoptosis of CAR cells. To further examine whether the observed suppression of cell viability involved in apoptotic machinery, the cells were treated with $20 \mu \mathrm{g} / \mathrm{ml}$ cetuximab, or $40 \mu \mathrm{M}$ curcumin, or both, for $24 \mathrm{~h}$ prior to determination of caspase- 3 and caspase- 9 activities. Individual treatment with cetuximab and curcumin induced 1.6- and 4.9-fold increases in caspase-3 activity compared with control, whereas combination treatment stimulated a 6.8-fold increase in the activity of caspase-3 of CAR cells (Fig. 3A). Similarly, caspase-9 activity was synergistically increased in CAR cells when treated with cetuximab and curcumin (6.0-fold increase; Fig. 3B). However, either curcumin or cetuximab alone stimulated more minor effects on caspase-9 activity, causing 1.5- and 3.6-fold increases in CAR cells. These results indicate the synergistic cytotoxicity of curcumin and cetuximab, and that the apoptotic mechanism was caspase-3/-9-dependent in CAR cells.
Effect of curcumin and/or cetuximab treatment on EGFR and MAPKs-regulated molecular signaling in CAR cells. Cetuximab was reported to inhibit tumor growth, invasion, angiogenesis and metastasis by binding to the extracellular domain of EGFR by regulating the MAPKs pathway $(12,13)$. Furthermore, it has been documented that colorectal cancer-cell resistance to cisplatin chemotherapy may involve MAPK signaling (41). The present study further analyzed the expression levels of EGFR and the downstream MAPK pathway in CAR cells prior to cetuximab or curcumin treatment, alone or in combination, using western blot analysis. It was demonstrated that treatment combination treatment effectively inhibited the phosphorylation of EGFR, but no effect on total EGFR protein level was observed in CAR cells (Fig. 4). The levels of phosphorylated MAPKs (ERK, JNK and p38) were also synergistically decreased compared with cetuximab or curcumin treatment alone. However, there was no effect on total ERK, JNK or p38 protein expression levels in any treatment group (Fig. 4). Taken together, these results suggest that combined use of cetuximab and curcumin triggered a dramatic increase in CAR-cell apoptosis by suppressing EGFR and MAPKs signaling (Fig. 5), suggesting that the synergic effects resulted in enhanced oral anticancer activity compared with single-drug treatment in resistant oral cancer cells.

\section{Discussion}

Surgery and brachytherapy are the major therapies for oral cancer in the T1, T2 and artificial T3 groups (Tumor-Node-Metastasis classification) in clinical practice guidelines for head and neck cancer in Japan (42). Platinum-based chemotherapy (cisplatin or carboplatin) is used for advanced stage cancer $(42,43)$. In 1978, cisplatin was approved by the Food and Drug Administration (FDA) for oral cancer treatment (44). Cisplatin is used for oral cancer chemotherapy and functions via direct reaction with cellular nucleophiles to achieve inter- and intra-stand DNA cross-links and protein cross-links with DNA and RNA (45). However, oral cancer cells have gained resistance to chemotherapeutic agents $(46,47)$. Several molecular mechanisms are involved in cisplatin-resistance: i) Increased activity of transporter protein function (MDR1 or p-glycoprotein); ii) activated drug metabolism activity by enzymes; iii) decreased drug binding to DNA; iv) promoted ROS production; v) stimulated DNA repair; vi) increased tolerance to DNA damage; vii) altered transcription of target genes; viii) changes in cell cycle-associated events and ix) inhibition of cell death (46-48). Recently, EGFR has been demonstrated as an important therapeutic target in oral cancer, and it is expressed more highly in oral cancer tissue than in normal tissues $(7,10)$. In addition, a correlation between high EGFR expression and radio-resistance was demonstrated in patients with oral cancer (49). Kuroda et al (50) demonstrated that cisplatin-resistance is associated with EGFR-mediated signaling in lung cancer A549 cells. Chemo-sensitivity to cisplatin was restored by an EGFR-selective tyrosine kinase inhibitor (AG1478) in A549 cells, suggesting that the EGFR inhibitor may be a therapy for cisplatin-resistance (50). To the best of our knowledge, this is the first study to report 

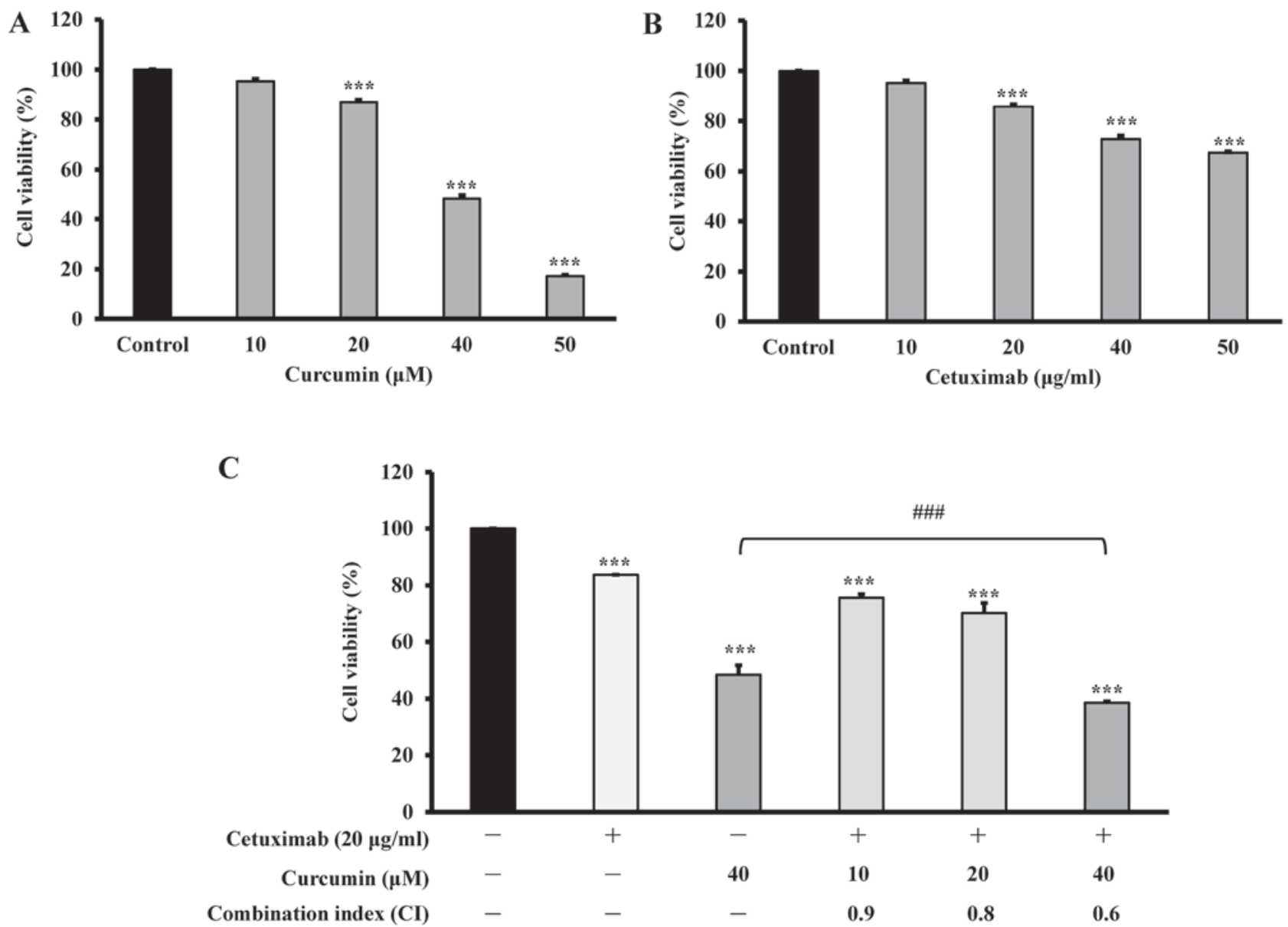

Figure 1. Cytotoxic effects of curcumin and cetuximab on CAR cells. The concentration-response curves of (A) curcumin, (B) cetuximab and (C) combined treatment. Cell viability was measured by MTT assay. Each data point is presented as the mean \pm standard deviation of 3 independent experiments. ${ }^{* * * *} \mathrm{P}<0.001$ vs. untreated control. ${ }^{\# \#} \mathrm{P}<0.001$ vs. curcumin $(40 \mu \mathrm{M})$ treatment only group.

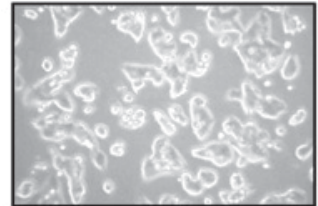

Control

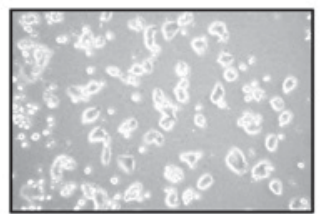

Cetuximab

$+$

Curcumin $10 \mu \mathrm{M}$

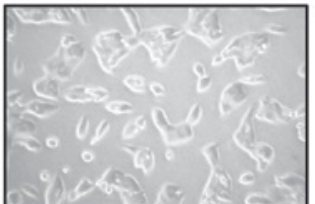

Cetuximab

$20 \mu \mathrm{g} / \mathrm{ml}$

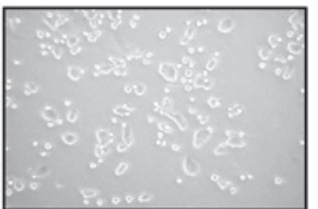

Cetuximab

$+$

Curcumin $20 \mu \mathrm{M}$

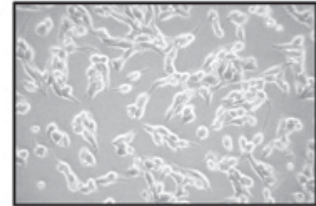

Curcumin

$10 \mu \mathrm{M}$

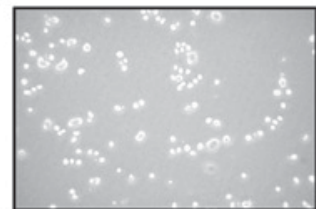

Cetuximab

$+$

Curcumin

$40 \mu \mathrm{M}$

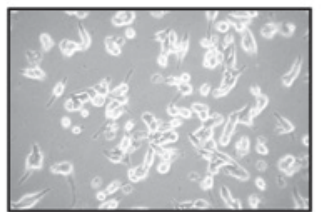

Curcumin $20 \mu \mathrm{M}$

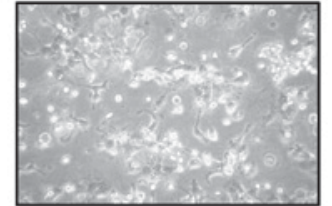

Curcumin $40 \mu \mathrm{M}$

Figure 2. Effects of curcumin and cetuximab on CAR cell morphology. The phase contrast microscopy images represent the results from 1 of 3 independent experiments at $\times 200$ magnification.

the synergistic inhibitory effect of cetuximab (an EGFR inhibitor) and curcumin in cisplatin-resistant human oral cancer cells.
Evidence indicates that the molecular mechanisms of cetuximab anticancer activity take 2 forms $(51,52)$. Firstly, EGF binding to the EGFR extracellular domain to inhibit 
A

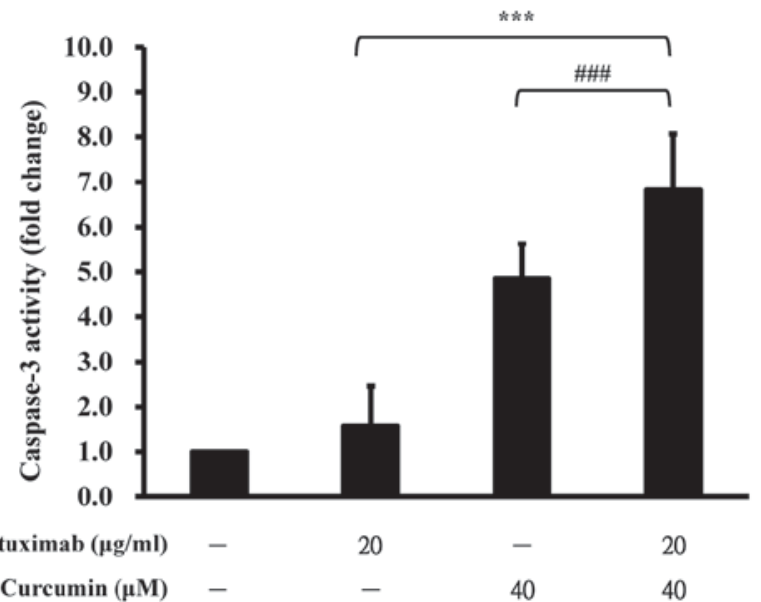

B

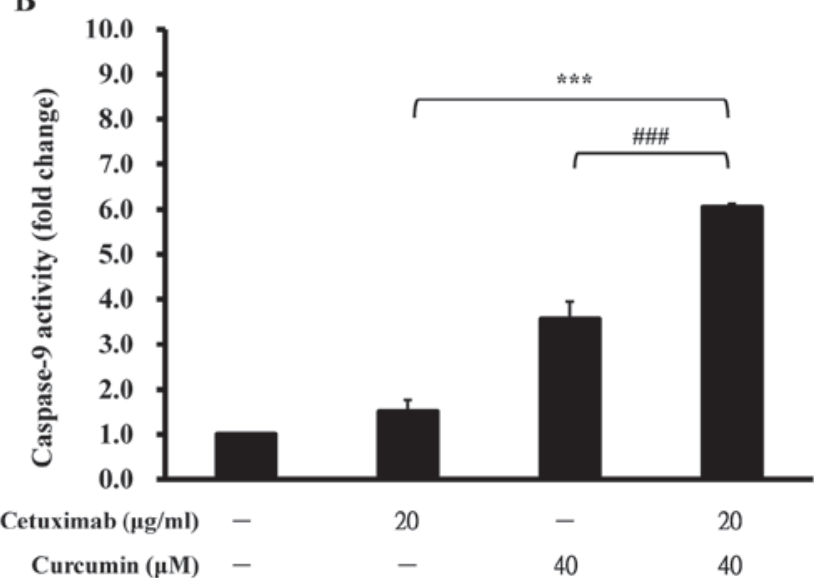

Figure 3. Effects of curcumin and cetuximab on caspase- 3 and caspase- 9 activities in CAR cells. (A) Caspase- 3 and (B) caspase- 9 activities were detected by colorimetric assay. Results are represented as the mean \pm standard deviation of 3 independent experiments. ${ }^{* * *} \mathrm{P}<0.001 \mathrm{vs}$. untreated control. ${ }^{\# \# \#} \mathrm{P}<0.001 \mathrm{vs}$. curcumin $(40 \mu \mathrm{M})$ treatment only group.

Treatment

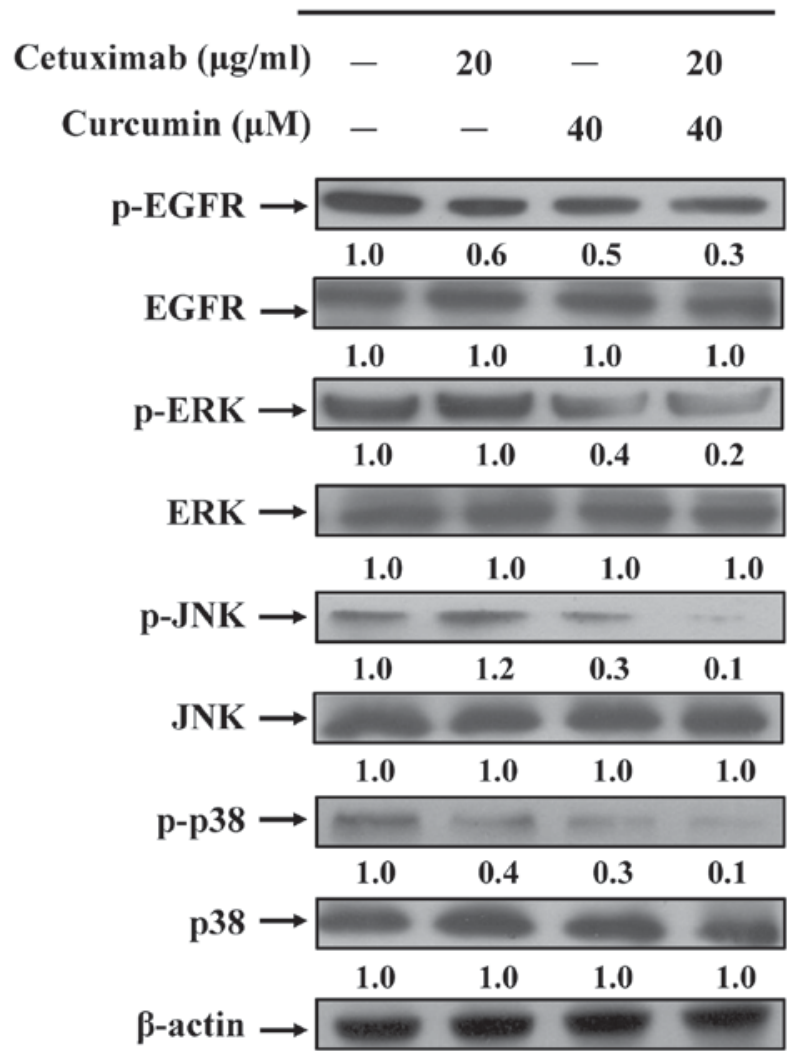

Figure 4. Effects of curcumin and cetuximab on EGFR and MAPK-regulated signaling in CAR cells. Protein expression of p-EGFR, EFGR, p-ERK, ERK, p-JNK, JNK, p-p38 and p38 were determined, and a $\beta$-actin control was applied to ensure equal loading. Representative images were taken from 3 independent experiments. EGFR, epidermal growth factor receptor; MAPK, mitogen activated protein kinase; p-, phosphorylated; ERK, extracellular signal-regulated kinase; JNK, c-Jun N-terminal kinase.

subsequent receptor dimerization/activation and to induce EGFR degradation is inhibited. Secondly, antibody-dependent cellular cytotoxicity or complement-dependent cell-mediated cytotoxicity $(51,52)$. Curcumin has been

\section{Curcumin}

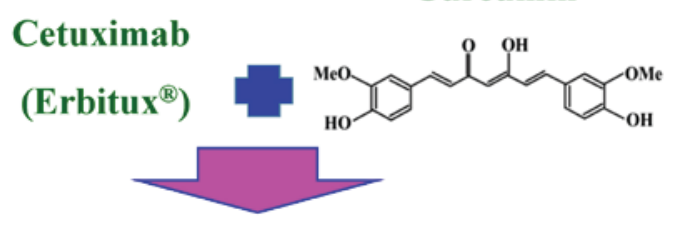

Synergistic effects
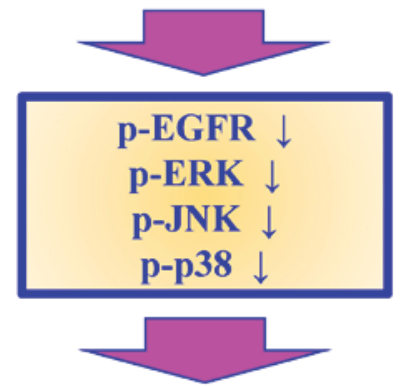

Caspase-9 $\uparrow$

Caspase-3

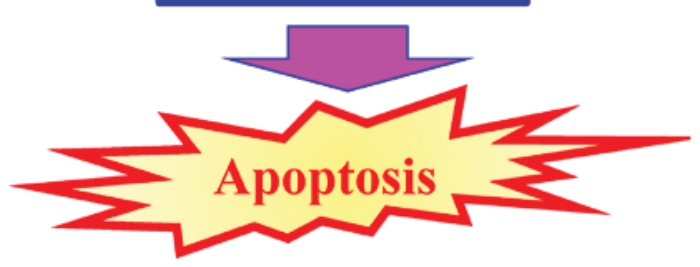

Figure 5. The underlying molecular mechanisms of combinatorial curcumin and cetuximab treatment. EGFR/MAPK signaling provokes a pro-apoptotic mechanism in human cisplatin-resistant oral cancer CAR cells. EGFR, epidermal growth factor receptor; MAPK, mitogen activated protein kinase; p-, phosphorylated; ERK, extracellular signal-regulated kinase; JNK, c-Jun N-terminal kinase.

historically used in traditional Chinese medicine, and its anticancer effects on various types of solid cancers, such as colon cancer, multiple myeloma and pancreatic cancer have reached phase II and III clinical trials $(53,54)$. Curcumin is also a potential therapeutic agent for the treatment of 
diabetic patients $(55,56)$. It has been reported that curcumin is able to directly but partially inhibit the enzymatic activity of the EGFR intracellular domain. Inhibition of EGFR phosphorylation and induction of EGFR ubiquitination then block the EGFR signaling pathway in cancer cells (57). However, it has not been reported whether combined cetuximab with curcumin synergistically inhibit drug-resistant oral cancer-cell proliferation. The present results demonstrated that a combined treatment of cetuximab and curcumin synergistically inhibited cell viability (Figs. 1B and 2), induced cell death (Fig. 2), and stimulated caspase-3 and caspase-9 activities (Fig. 3). Furthermore, curcumin dramatically enhanced cetuximab-suppressed phosphorylation of EGFR, ERK, JNK, and p38 levels in CAR cells (Fig. 4). A previous study by Son et al (58) demonstrated the effect of cetuximab combined with cisplatin on colon cancer growth. Cetuximab significantly decreased phosphorylation of EGFR and phosphorylated p38/p38 ratio at $30 \mu \mathrm{g} / \mathrm{ml}$, but there was no effect on the phosphorylated ERK/ERK ratio in colon cancer HCT116 cells. The present study also demonstrated that cetuximab treatment decreased the protein level of phosphorylated EGFR and phosphorylated p38. In addition, Li et al (59) demonstrated that the EGFR monoclonal antibody, cetuximab, mildly evoked apoptosis of human vulvar squamous carcinoma A431 cells. This is consistent with the present finding that cetuximab triggered a non-significant increase in caspase- 3 and caspase- 9 activities in CAR cells. However, the activities of caspase-3 and caspase- 9 were dramatically enhanced in CAR cells prior to treatment with cetuximab in combination with curcumin; or with exposure only to curcumin. The present results are also consistent with previous studies $(26,31)$ showing that curcumin is effective against various types of cancer via intrinsic apoptotic function. Although curcumin possesses powerful biological activities, it does not reach the criteria of a good drug candidate because it lacks adequate water solubility and high bioavailability, and undergoes rapid in vivo metabolism (60). To overcome these limitations, novel forms of curcumin targeting, including nanoparticles, liposomes, cyclodextrin encapsulation, micelles and phospholipid complexes, have been synthesized and tested in recent years $(61,62)$.

In conclusion, combined cetuximab and curcumin treatment is a novel therapeutic option for oral cancer treatment, exhibiting synergistic anti-proliferative activity. The mechanism results in a decreased activated EGFR level in cisplatin-resistant oral cancer cells. With the results presented in the present study, curcumin could be used as an adjuvant drug, and the combination of cetuximab and curcumin may be a strategy to pursue in clinical trials.

\section{Acknowledgements}

The authors would like to thank Dr Hong-Yi Chiu of Department of Pharmacy, Hualien Tzu Chi Hospital (Taiwan) for providing cetuximab (Erbitux) as a gift.

\section{Funding}

The present study was supported by China Medical University Hospital (grant no. DMR-107-1230).

\section{Availability of data and materials}

The datasets used and/or analyzed during the current study are available from the corresponding author on reasonable request.

\section{Authors' contributions}

CFC, HJH and TDW conceived and designed the experiments; CFC, CCL, JHC, HYC, JSY, and CYL performed the experiments. CFC, CCL, JHC, and JSY analysed the data; CFC, HJH and TDW wrote and modified the manuscript. All authors read and approved the final manuscript.

\section{Ethics approval and consent to participate}

Not applicable.

\section{Patient consent for publication}

Not applicable.

\section{Competing interests}

The authors declare that they have no competing interests.

\section{References}

1. Horn D, Hess J, Freier K, Hoffmann J and Freudlsperger C: Targeting EGFR-PI3K-AKT-mTOR signaling enhances radiosensitivity in head and neck squamous cell carcinoma. Expert Opin Ther Targets 19: 795-805, 2015.

2. Prince A, Aguirre-Ghizo J, Genden E, Posner M and Sikora A Head and neck squamous cell carcinoma: New translational therapies. Mt Sinai J Med 77: 684-699, 2010.

3. Mendelsohn $\mathbf{J}$ and Baselga J: Epidermal growth factor receptor targeting in cancer. Semin Oncol 33: 369-385, 2006.

4. Todd R and Wong DT: Epidermal growth factor receptor (EGFR) biology and human oral cancer. Histol Histopathol 14: 491-500, 1999.

5. Pickhard A, Siegl M, Baumann A, Huhn M, Wirth M, Reiter R, Rudelius M, Piontek G and Brockhoff G: The response of head and neck squamous cell carcinoma to cetuximab treatment depends on Aurora kinase A polymorphism. Oncotarget 5: 5428-5438, 2014.

6. Lin MC, Huang MJ, Liu CH, Yang TL and Huang MC: GALNT2 enhances migration and invasion of oral squamous cell carcinoma by regulating EGFR glycosylation and activity. Oral Oncol 50: 478-484, 2014.

7. Cassell A and Grandis JR: Investigational EGFR-targeted therapy in head and neck squamous cell carcinoma. Expert Opin Investig Drugs 19: 709-722, 2010.

8. Hoch MA, Cousins K, Nartey R, Riley K and Hartranft M: Two cases of combination therapy with cetuximab, paclitaxel, and cisplatin for advanced head and neck cancer. J Oncol Pharm Pract 1078155217722406, 2017.

9. Liebig H, Günther G, Kolb M, Mozet C, Boehm A, Dietz A and Wichmann G: Reduced proliferation and colony formation of head and neck squamous cell carcinoma (HNSCC) after dual targeting of EGFR and hedgehog pathways. Cancer Chemother Pharmacol 79: 411-420, 2017.

10. Moon C, Chae YK and Lee J: Targeting epidermal growth factor receptor in head and neck cancer: Lessons learned from cetuximab. Exp Biol Med (Maywood) 235: 907-920, 2010.

11. Astsaturov I, Cohen RB and Harari P: EGFR-targeting monoclonal antibodies in head and neck cancer. Curr Cancer Drug Targets 6: 691-710, 2006.

12. Dai W, Li Y, Zhou Q, Xu Z, Sun C, Tan X and Lu L: Cetuximab inhibits oral squamous cell carcinoma invasion and metastasis via degradation of epidermal growth factor receptor. J Oral Pathol Med 43: 250-257, 2014. 
13. Psyrri A, Seiwert TY and Jimeno A: Molecular pathways in head and neck cancer: EGFR, PI3K, and more. Am Soc Clin Oncol Educ Book: 246-255, 2013.

14. Astsaturov I, Cohen RB and Harari P: EGFR-targeting monoclonal antibodies in head and neck cancer. Curr Cancer Drug Targets 7: 650-665, 2007.

15. Burgy M, Barthélémy P, Lefevre F, Dupret-Bories A, Truntzer P, Korenbaum C, Flesch H, Bronner G and Borel C: Cetuximab-carboplatin-5-fluorouracil regimen in elderly patients with recurrent or metastatic head and neck squamous-cell carcinoma: A French retrospective survey. Oncology 93: 11-17, 2017.

16. Guigay J, Even C, Mayache-Badis L, Debbah M, Saada-Bouzid E, Tao Y, Deschamps F, Janot F, Lezghed N and Michel C: Long-term response in patient with recurrent oropharyngeal carcinoma treated with cetuximab, docetaxel and cisplatin (TPEx) as first-line treatment followed by cetuximab maintenance. Oral Oncol 68: 114-118, 2017.

17. Unlu A, Nayir E, Dogukan Kalenderoglu M, Kirca O and Ozdogan M: Curcumin (Turmeric) and cancer. J BUON 21: 1050-1060, 2016.

18. He Y, Yue Y, Zheng X, Zhang K, Chen S and Du Z: Curcumin, inflammation, and chronic diseases: How are they linked? Molecules 20: 9183-9213, 2015.

19. Wang J and Jiang YF: Natural compounds as anticancer agents: Experimental evidence. World J Exp Med 2: 45-57, 2012.

20. Chen ZF and Liang H: Progresses in TCM metal-based antitumour agents. Anticancer Agents Med Chem 10: 412-423, 2010.

21. Pandima Devi K, Rajavel T, Daglia M, Nabavi SF, Bishayee A and Nabavi SM: Targeting miRNAs by polyphenols: Novel therapeutic strategy for cancer. Semin Cancer Biol 46: 146-157, 2017.

22. Owen HC, Appiah S, Hasan N, Ghali L, Elayat G and Bell C: Phy tochemical modulation of apoptosis and autophagy: Strategies to overcome chemoresistance in leukemic stem cells in the bone marrow microenvironment. Int Rev Neurobiol 135: 249-278, 2017.

23. Karimian MS, Pirro M, Johnston TP, Majeed M and Sahebkar A Curcumin and endothelial function: Evidence and mechanisms of protective effects. Curr Pharm Des 23: 2462-2473, 2017.

24. Jha A, Mohapatra PP, AlHarbi SA and Jahan N: Curcumin: Not so spicy after all. Mini Rev Med Chem 17: 1425-1434, 2017.

25. Peng SF, Lee CY, Hour MJ, Tsai SC, Kuo DH, Chen FA, Shieh PC and Yang JS: Curcumin-loaded nanoparticles enhance apoptotic cell death of U2OS human osteosarcoma cells through the Akt-Bad signaling pathway. Int J Oncol 44: 238-246, 2014.

26. Borges GÁ, Rêgo DF, Assad DX, Coletta RD, De Luca Canto G and Guerra EN: In vivo and in vitro effects of curcumin on head and neck carcinoma: A systematic review. J Oral Pathol Med 46 3-20, 2017

27. Vander Broek R, Snow GE, Chen Z and Van Waes C: Chemoprevention of head and neck squamous cell carcinoma through inhibition of NF-kB signaling. Oral Oncol 50: 930-941, 2014.

28. Agrawal DK and Mishra PK: Curcumin and its analogues: Potential anticancer agents. Med Res Rev 30: 818-860, 2010.

29. Lin JK: Molecular targets of curcumin. Adv Exp Med Biol 595: 227-243, 2007

30. Fetoni AR, Paciello F, Mezzogori D, Rolesi R, Eramo SL, Paludetti G and Troiani D: Molecular targets for anticancer redox chemotherapy and cisplatin-induced ototoxicity: The role of curcumin on pSTAT3 and Nrf-2 signalling. Br J Cancer 113: 1434-1444, 2015

31. Sivanantham B, Sethuraman S and Krishnan UM: Combinatorial effects of curcumin with an anti-neoplastic agent on head and neck squamous cell carcinoma through the regulation of EGFR-ERK1/2 and apoptotic signaling pathways. ACS Comb Sci 18: 22-35, 2016.

32. Gosepath EM, Eckstein N, Hamacher A, Servan K, von Jonquieres G, Lage H, Györffy B, Royer HD and Kassack MU: Acquired cisplatin resistance in the head-neck cancer cell line Cal27 is associated with decreased DKK1 expression and can partially be reversed by overexpression of DKK1. Int J Cancer 123: 2013-2019, 2008.

33. Chang PY, Peng SF, Lee CY, Lu CC, Tsai SC, Shieh TM, Wu TS, Tu MG, Chen MY and Yang JS: Curcumin-loaded nanoparticles induce apoptotic cell death through regulation of the function of MDR1 and reactive oxygen species in cisplatin-resistant CAR human oral cancer cells. Int J Oncol 43: 1141-1150, 2013.

34. Lee MR, Lin C, Lu CC, Kuo SC, Tsao JW, Juan YN, Chiu HY, Lee FY, Yang JS and Tsai FJ: YC-1 induces $G_{0} / G_{1}$ phase arrest and mitochondria-dependent apoptosis in cisplatin-resistant human oral cancer CAR cells. Biomedicine (Taipei) 7: 12, 2017.
35. Lu CC, Yang JS, Chiang JH, Hour MJ, Lin KL, Lee TH and Chung JG: Cell death caused by quinazolinone HMJ-38 challenge in oral carcinoma CAL 27 cells: Dissections of endoplasmic reticulum stress, mitochondrial dysfunction and tumor xenografts. Biochim Biophys Acta 1840: 2310-2320, 2014.

36. Xu Y, Xin Y, Diao Y, Lu C, Fu J, Luo L and Yin Z: Synergistic effects of apigenin and paclitaxel on apoptosis of cancer cells. PLoS One 6: e29169, 2011.

37. Lu CC, Huang BR, Liao PJ and Yen GC: Ursolic acid triggers nonprogrammed death (necrosis) in human glioblastoma multiforme DBTRG-05MG cells through MPT pore opening and ATP decline. Mol Nutr Food Res 58: 2146-2156, 2014

38. Chiang JH, Yang JS, Lu CC, Hour MJ, Chang SJ, Lee TH and Chung JG: Newly synthesized quinazolinone HMJ-38 suppresses angiogenetic responses and triggers human umbilical vein endothelial cell apoptosis through p53-modulated Fas/death receptor signaling. Toxicol Appl Pharmacol 269: 150-162, 2013.

39. Ma YS, Weng SW, Lin MW, Lu CC, Chiang JH, Yang JS, Lai KC, Lin JP, Tang NY, Lin JG and Chung JG: Antitumor effects of emodin on LS1034 human colon cancer cells in vitro and in vivo: Roles of apoptotic cell death and LS1034 tumor xenografts model. Food Chem Toxicol 50: 1271-1278, 2012

40. Huang WW, Chiu YJ, Fan MJ, Lu HF, Yeh HF, Li KH, Chen PY, Chung JG and Yang JS: Kaempferol induced apoptosis via endoplasmic reticulum stress and mitochondria-dependent pathway in human osteosarcoma U-2 OS cells. Mol Nutr Food Res 54: $1585-1595,2010$

41. Grossi V, Peserico A, Tezil T and Simone C: p38alpha MAPK pathway: A key factor in colorectal cancer therapy and chemoresistance. World J Gastroenterol 20: 9744-9758, 2014.

42. Nibu KI, Hayashi R, Asakage T, Ojiri H, Kimata Y, Kodaira T, Nagao T, Nakashima T, Fujii T, Fujii H, et al: Japanese clinical practice guideline for head and neck cancer. Auris Nasus Larynx 44: 375-380, 2017.

43. Brockstein BE and Vokes EE: Oral chemotherapy in head and neck cancer. Drugs 58 (Suppl 3): S91-S97, 1999.

44. Köberle B, Tomicic MT, Usanova S and Kaina B: Cisplatin resistance: Preclinical findings and clinical implications. Biochim Biophys Acta 1806: 172-182, 2010.

45. Carlsson L, Bratman SV, Siu LL and Spreafico A: The cisplatin total dose and concomitant radiation in locoregionally advanced head and neck cancer: Any recent evidence for dose efficacy? Curr Treat Options Oncol 18: 39, 2017.

46. Wang C, Liu XQ, Hou JS, Wang JN and Huang HZ: Molecular mechanisms of chemoresistance in oral cancer. Chin J Dent Res 19: 25-33, 2016.

47. Dasari S and Tchounwou PB: Cisplatin in cancer therapy: Molecular mechanisms of action. Eur J Pharmacol 740: 364-378, 2014.

48. Brozovic A: The relationship between platinum drug resistance and epithelial-mesenchymal transition. Arch Toxicol 91: 605-619, 2017.

49. Alorabi M, Shonka NA and Ganti AK: EGFR monoclonal antibodies in locally advanced head and neck squamous cell carcinoma: What is their current role? Crit Rev Oncol Hematol 99: 170-179, 2016.

50. Kuroda H, Takeno M, Murakami S, Miyazawa N, Kaneko T and Ishigatsubo Y: Inhibition of heme oxygenase-1 with an epidermal growth factor receptor inhibitor and cisplatin decreases proliferation of lung cancer A549 cells. Lung Cancer 67: 31-36, 2010.

51. Seo Y, Ishii Y, Ochiai H, Fukuda K, Akimoto S, Hayashida T, Okabayashi K, Tsuruta M, Hasegawa $\mathrm{H}$ and Kitagawa $\mathrm{Y}$ : Cetuximab-mediated ADCC activity is correlated with the cell surface expression level of EGFR but not with the KRAS/BRAF mutational status in colorectal cancer. Oncol Rep 31: 2115-2122, 2014.

52. Kondo N, Tsukuda M, Sakakibara A, Takahashi H, Hyakusoku H, Komatsu M, Niho T, Nakazaki K and Toth G: Combined molecular targeted drug therapy for EGFR and HER-2 in head and neck squamous cell carcinoma cell lines. Int J Oncol 40: 1805-1812, 2012

53. Ji JL, Huang XF and Zhu HL: Curcumin and its formulations: Potential anti-cancer agents. Anticancer Agents Med Chem 12: 210-218, 2012.

54. Shehzad A, Wahid F and Lee YS: Curcumin in cancer chemoprevention: Molecular targets, pharmacokinetics, bioavailability, and clinical trials. Arch Pharm (Weinheim) 343: 489-499, 2010 . 
55. Qadir MI, Naqvi ST and Muhammad SA: Curcumin: A polyphenol with molecular targets for cancer control. Asian Pac J Cancer Prev 17: 2735-2739, 2016.

56. Weisberg S, Leibel R and Tortoriello DV: Proteasome inhibitors, including curcumin, improve pancreatic $\beta$-cell function and insulin sensitivity in diabetic mice. Nutr Diabetes 6: e205, 2016.

57. Lee JY, Lee YM, Chang GC, Yu SL, Hsieh WY, Chen JJ, Chen HW and Yang PC: Curcumin induces EGFR degradation in lung adenocarcinoma and modulates p38 activation in intestine: The versatile adjuvant for gefitinib therapy. PLoS One 6: e23756, 2011.

58. Son DJ, Hong JE, Ban JO, Park JH, Lee HL, Gu SM, Hwang JY, Jung MH, Lee DW, Han SB and Hong JT: Synergistic inhibitory effects of cetuximab and cisplatin on human colon cancer cell growth via inhibition of the ERK-dependent EGF receptor signaling pathway. Biomed Res Int 2015: 397563, 2015.

59. $\mathrm{Li} \mathrm{X}, \mathrm{Lu} \mathrm{Y}, \mathrm{Pan} \mathrm{T}$ and Fan Z: Roles of autophagy in cetuximab-mediated cancer therapy against EGFR. Autophagy 6: 1066-1077, 2010
60. Douglass BJ and Clouatre DL: Beyond yellow curry: Assessing commercial curcumin absorption technologies. J Am Coll Nutr 34: 347-358, 2015.

61. Chang LC, Hsieh MT, Yang JS, Lu CC, Tsai FJ, Tsao JW, Chiu YJ, Kuo SC and Lee KH: Effect of bis(hydroxymethyl) alkanoate curcuminoid derivative MTH-3 on cell cycle arrest, apoptotic and autophagic pathway in triple-negative breast adenocarcinoma MDA-MB-231 cells: An in vitro study. Int J Oncol 52: 67-76, 2018

62. Hsieh MT, Chang LC, Hung HY, Lin HY, Shih MH, Tsai CH, Kuo SC and Lee KH: New bis(hydroxymethyl) alkanoate curcuminoid derivatives exhibit activity against triple-negative breast cancer in vitro and in vivo. Eur J Med Chem 131: 141-151, 2017.

(i) (5) This work is licensed under a Creative Commons Attribution-NonCommercial-NoDerivatives 4.0 International (CC BY-NC-ND 4.0) License. 